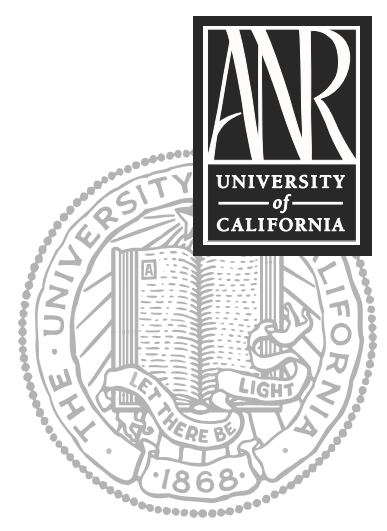

UNIVERSITY OF CALIFORNIA

Division of Agriculture and Natural Resources http://anrcatalog.ucdavis.edu

\title{
NUTRITION AND HEALTH INFO SHEET Fiber
}

ANDREA BERSAMIN, Post Doctoral Scholar, School of Medicine, Stanford University; CRISTY HATHAWAY, Research Assistant; Department of Nutrition, University of California, Davis; KARRIE HENEMAN, Assistant Project Scientist, Department of Nutrition, University of California, Davis; SHERI ZIDENBERG-CHERR, UC Cooperative Extension Nutrition Science Specialist, Department of Nutrition, University of California, Davis

\section{SOME FACTS ABOUT FIBER}

\section{What is fiber?}

Multiple definitions of total fiber are recognized; however, the most recently accepted definition considers it the sum of dietary fiber and functional fiber. Dietary fiber, also called roughage, bulk, and viscous fiber, includes nondigestible carbohydrates and lignin most commonly found in plants. Functional fiber is defined as isolated, manufactured, or synthetic oligosaccharides with three or more degrees of polymerization, and it is found in both plants and animal products. Fiber plays an important role in several physiological functions and has beneficial effects on laxation, blood glucose, and cholesterol concentrations. ${ }^{1}$ Fiber has also been implicated in reducing the incidence of diverticulosis, cardiovascular disease, and some cancers. ${ }^{1,2}$

\section{What is the difference between soluble (viscous) and insoluble fiber?}

Historically, fiber has been classified as soluble (gums, mucilages, and pectins), now referred to as viscous, and insoluble (cellulose, hemicellulose, and lignin). These classifications were intended to predict physiological outcomes but this has been increasingly questioned by further studies. ${ }^{4}$ The United Nations, in a joint FAO/WHO report, proposed that these terms be phased out, but nutritionists continue to rely on them heavily. ${ }^{5}$

\section{What are good sources of fiber?}

Whole grain products, vegetables, and fruits are the principal sources of fiber in our diet. According to the U.S. Food and Drug Administration (FDA) label content laws, the term high fiber indicates a food that has at least 20 percent of the Adequate Intake (AI) for fiber, and a good source of fiber food must have between 10 and 15 percent of the AI for fiber. ${ }^{6}$ There is no fiber in meat, fish, eggs, milk, or cheese.

\section{Grain products}

Whole grain flour and foods made from whole grains contribute the greatest amount of fiber in the diet compared with other food sources. Rye is highest on the list, followed by wheat, barley, oats, brown rice, and corn meal. Bran (the outer layer of the grain kernel) contains most of the fiber in a grain (up to 90 percent, depending on how it is processed).

\section{Vegetables}

Legumes (dried beans, peas, and lentils) are the highest source of total fiber among vegetable sources. Potatoes, carrots, cabbage, and tomatoes have lower fiber content, but they often contribute more fiber to our daily diet because we eat them more frequently. Vegetables tend to have less fiber than cereals because they are higher in water content. 


\section{What is meant by whole grain?}

The term whole grain refers to a grain that has not been refined by having any of its parts removed, including the germ, the bran, and the endosperm. During the milling process in the production of white flour, for example, only the endosperm is used and the remaining layers are discarded. As a result, the other layers-rich sources of nutrients, including fiber-are lost. ${ }^{6}$ Although many nutrients are added back to enrich refined grains, high-fiber plant foods (such as whole wheat flour and breads along with brown rice) are higher in a number of nutrients that are not added during the enrichment process.

\section{Why do people need fiber?}

Eating foods with fiber is important for proper bowel function and can reduce symptoms of chronic constipation, diverticulosis, and hemorrhoids. Populations with low intakes of dietary fiber may have more heart disease, obesity, and some cancers. Fiber is associated with a reduced incidence of these chronic health problems, although the precise protective factor is yet unknown. ${ }^{2}$

\section{Fiber and colon health}

Fiber promotes healthy bowel function, due to microflora activity, water holding capacity, increasing fecal bulk, and reducing fecal transit time, thereby preventing constipation. ${ }^{2}$ Fiber is fermented by microflora that reside in the large intestine, which produce butyrate. Butyrate is the preferred source of energy for colon cells; furthermore, theories suggest that an absence of butyrate may contribute to colon cancer and ulcerative colitis. ${ }^{1}$

\section{Fiber and heart disease}

Foods rich in fiber have been associated with reducing cholesterol concentration, particularly LDL cholesterol, which is associated with increased risk for cardiovascular disease. The mechanism, though not fully understood, may be related to the viscous property of some fiber. ${ }^{1}$

\section{Fiber and obesity}

Fiber may also assist in preventing obesity because of its ability to hold water, thereby creating more bulk to help the stomach feel full. Some fibers empty from the stomach more slowly, which prolongs satiety.

\section{Fiber and cancer}

An association between high-fiber intake and a reduced incidence of some cancers has been observed. This protective factor has not been linked to the fiber alone, however, and may be due to an interaction among other components in the food. ${ }^{2}$

\section{Fiber and diabetes}

In people with diabetes, a diet high in viscous fiber, especially from whole grains, can help control blood glucose concentration by slowing down the rate of nutrient absorption. ${ }^{1,6}$

\section{How much fiber is recommended?}

According to a recent study, women eat between 12.1 to 13.8 grams per day of fiber and men eat between 16.5 and 17.9 grams per day of fiber. (See the metric conversion table at the end of this publication.) The current Adequate Intake (AI) for fiber as recommended by the Institute of Medicine and the Food and Nutrition Board indicate 25 and 38 grams per day for women and men, respectively, based on health benefits from fiber that protect against coronary heart disease. ${ }^{1}$ 


\section{What are some ways to increase fiber intake?}

To increase fiber intake, the following suggestions quoted from the Dietary Guidelines for Americans apply on a daily basis for adults and children over 2 years of age:

- Consume a sufficient amount of fruits and vegetables while staying within energy needs. Two cups of fruit and $2 \frac{1}{2}$ cups of vegetables per day are recommended for a reference 2,000-calorie intake, with higher or lower amounts depending on the calorie level.

- Choose a variety of fruits and vegetables each day. In particular, select from all five vegetable subgroups (dark green, orange, legumes, starchy vegetables, and other vegetables) several times a week.

- Consume 3 or more ounce-equivalents of whole-grain products per day, with the rest of the recommended grains coming from enriched or whole-grain products. In general, at least half the grains should come from whole grains. ${ }^{7}$

Other ways to increase fiber intake include the following suggestions:

- Use fresh or dried fruits for desserts and snacks.

- Use beans, lentils, and peas. Add cooked beans and peas to soups, stews, casseroles, and salads. Nuts and seeds, although high in fiber, are also high in fat, so use them sparingly.

- Choose whole grain breads and cereals, and check the ingredient label to make sure the food is really whole grain.

- Choose high fiber grains such as buckwheat, brown rice, and bulgur. Choose them in place of white rice or a white flour product as a side dish, in pilaf, and in soups and stews.

- Leave the skin on potatoes, fruits, and vegetables. This outer layer is high in fiber.

\section{Can too much fiber be harmful?}

Eating too much fiber (more than 50 to 60 grams of fiber per day) may decrease the amount of vitamins and minerals your body absorbs. To add more fiber to the diet, an individual can increase the amount eaten gradually; this gives the stomach and intestines time to get used to the change. Fiber supplements can easily lead to excess, which may cause intestinal discomfort; thus, a safer route to adding fiber to the diet is by eating more fiber-rich foods. Eating too much fiber too quickly, however, may cause gas, diarrhea, and bloating. Studies suggest that proper hydration is essential in order for fiber to be beneficial; consequently, drinking at least 8 glasses of water and other liquids per day is recommended. ${ }^{1}$

Adding fiber to the diets of young children needs to be done carefully. Extra fiber may cause them to feel full too quickly and make it hard for them to eat enough food to grow properly. Too much fiber may interfere with the body's ability to obtain enough vitamins and minerals; this can be a problem with adults but is more serious in children.

It may be easy to overdo the intake of fiber in the case of elderly people, since they often have limited intake of food, and people who have had gastrointestinal surgery (on some part of the stomach, intestines, colon, or rectum). These people may feel the effects of added fiber more than others and should check with their physician before adding fiber to their diet. 


\section{Should people take fiber supplements?}

Excessive use of fiber supplements is associated with greater risk for intestinal problems. Some of the benefits from a high-fiber diet may be from the food that provides the fiber, not from the fiber alone. ${ }^{6}$ For this reason, it is best to obtain fiber from foods rather than from supplements. Following the guidelines above is one way to ensure that sufficient amounts of fiber are being consumed without going overboard.

\section{What is the fiber content of some common foods?}

\begin{tabular}{|c|c|c|c|}
\hline & Serving size & Dietary fiber (g) & Calories \\
\hline \multicolumn{4}{|l|}{ Breads, grains, and pasta } \\
\hline bagel & 1 & 1.2 & 163 \\
\hline rice, brown, cooked & $1 / 2$ cup & 1.7 & 109 \\
\hline spaghetti, cooked & $1 / 2$ cup & 1.1 & 99 \\
\hline whole wheat bread & 1 slice & 1.9 & 61 \\
\hline \multicolumn{4}{|l|}{ Breakfast cereals } \\
\hline All-Bran & $1 / 3$ cup & 8.5 & 71 \\
\hline Cheerios & 1 cup & 2.7 & 111 \\
\hline Oatmeal (regular, quick or instant), cooked & $3 / 4$ cup & 1.6 & 108 \\
\hline Raisin Bran & $3 / 4$ cup & 4.8 & 115 \\
\hline \multicolumn{4}{|l|}{ Fruits } \\
\hline apple (with skin) & 1 medium & 3.0 & 81 \\
\hline cantaloupe & $1 / 4$ & 1.1 & 47 \\
\hline fig, dried & 2 & 3.5 & 95 \\
\hline orange & 1 medium & 3.1 & 62 \\
\hline \multicolumn{4}{|l|}{ Legumes, cooked } \\
\hline baked beans (vegetarian or with pork), canned & $1 / 2$ cup & 9.8 & 118 \\
\hline lentils, cooked & $1 / 2$ cup & 3.7 & 97 \\
\hline \multicolumn{4}{|l|}{ Vegetables, cooked } \\
\hline broccoli & $1 / 2$ cup & 2.0 & 23 \\
\hline brussels sprouts & $1 / 2$ cup & 3.4 & 30 \\
\hline potato, baked (with skin) & 1 medium & 3.6 & 220 \\
\hline \multicolumn{4}{|l|}{ Vegetables, raw } \\
\hline carrots & 1 medium & 2.3 & 31 \\
\hline spinach & 1 cup & 1.5 & 12 \\
\hline tomato & 1 medium & 1.6 & 24 \\
\hline
\end{tabular}




\section{REFERENCES}

1. Standing Committee on the Scientific Evaluation of Dietary Reference Intakes, Food and Nutrition Board, Institute of Medicine. 2002. Dietary reference intakes for energy, carbohydrate, fiber, fat, fatty acids, cholesterol, protein, and amino acids (macronutrients). Washington, DC: National Academy Press.

2. Gallaher, D. D., and B. O. Schneeman. 2001. Dietary fiber. In E. E. Ziegler and L. J. Filer, eds., Present knowledge in nutrition. Washington DC: ILSI Press. 83-91.

3. FAO (Food and Agriculture Organization of the United Nations) and WHO (World Health Organization). 1997. Carbohydrates in human nutrition: Report of an expert meeting. FAO/WHO expert consultation on carbohydrates in human nutrition. Rome: FAO. 66:1-140.

4. Slavin, J. L., M. C. Martini, D. R. Jacobs, Jr., and L. Marquart. 1999. Plausible mechanisms for the protectiveness of whole grains. Am J Clin Nutri 70 (3 Suppl): 459S-463S. AJCN Web site, http://www.ajcn.org/cgi/content/ abstract/70/3/459S?ck=nck.

5. Chen, H. L., V. S. Haack, C. W. Janecky, N. W. Vollendorf, and J. A. Marlett. 1998. Mechanisms by which wheat bran and oat bran increase stool weight in humans. Am J Clin Nutri 68(3): 711-719.

6. FDA (U.S. Food and Drug Administration). 1999. Food labeling guide: Appendix B. Center for Food Safety and Applied Nutrition Web site, http://www.cfsan.fda.gov/ dms/flg-6b.html.

7. U.S. Department of Health and Human Services. 2005. Dietary Guidelines for Americans Web site, http://www.health.gov/dietaryguidelines/dga2005/ document/pdf/DGA2005.pdf.

8. USDA (U.S. Department of Agriculture). 2004. USDA Nutrient Data Laboratory Web site, http://www.nal.usda.gov/fnic/cgi-bin/nut_search.pl.

\section{METRIC CONVERSIONS}

\begin{tabular}{|l|c|c|l|}
\hline English & $\begin{array}{c}\text { Conversion factor for } \\
\text { English to metric }\end{array}$ & $\begin{array}{c}\text { Conversion factor for } \\
\text { metric to English }\end{array}$ & Metric \\
\hline grain & 64.80 & 0.015 & milligram (mg) \\
\hline fluid ounce (fl oz) & 29.57 & 0.034 & milliliter (ml) \\
\hline fluid ounce (fl oz) & 2.96 & 0.0034 & deciliter (dl) \\
\hline ounce (oz) & 28.35 & 0.035 & gram (g) \\
\hline cup & 236.60 & 0.004 & milliliter (ml) \\
\hline
\end{tabular}




\section{FOR FURTHER INFORMATION}

To order or obtain ANR publications and other products, visit the ANR Communication Services online catalog at http://anrcatalog.ucdavis.edu. You can also place orders by mail, phone, or FAX, or request a printed catalog of our products from

University of California

Agriculture and Natural Resources

Communication Services

6701 San Pablo Avenue, 2nd Floor

Oakland, California 94608-1239

Telephone 1-800-994-8849

(510) 642-2431

FAX (510) 643-5470

E-mail: danrcs@ucdavis.edu

An electronic version of this publication is available on the ANR Communication Services Web site at http://anrcatalog.ucdavis.edu.

This publication has been anonymously peer reviewed for technical accuracy by University of California scientists and other qualified professionals. This review process was managed by the ANR Associate Editor for Food and Nutrition.

Publication 8139

ISBN-13: 978-1-60107-496-6

(C) 2008 The Regents of the University of California

Division of Agriculture and Natural Resources

All rights reserved.

No part of this publication may be reproduced, stored in a retrieval system, or transmitted, in any form or by any means, electronic, mechanical, photocopying, recording, or otherwise, without the written permission of the publisher and the authors.

The University of California prohibits discrimination or harassment of any person on the basis of race, color, national origin, religion, sex, gender identity, pregnancy (including childbirth, and medical conditions related to pregnancy or childbirth), physical or mental disability, medical condition (cancer-related or genetic characteristics), ancestry, marital status, age, sexual orientation, citizenship, or status as a covered veteran (covered veterans are special disabled veterans, recently separated veterans, Vietnam era veterans, or any other veterans who served on active duty during a war or in a campaign or expedition for which a campaign badge has been authorized) in any of its programs or activities. University policy is intended to be consistent with the provisions of applicable State and Federal laws.

Inquiries regarding the University's nondiscrimination policies may be directed to the Affirmative Action/Staff Personnel Services Director, University of California, Agriculture and Natural Resources, 1111 Franklin Street, 6th Floor, Oakland, CA 94607-5201, (510) 987-0096. For information about ordering this publication, telephone 1-800-994-8849.

pr-1/08-LR/RW 